mathematicians. But even the most abstract mathematical ideas often find a function, and it's often physicists who benefit. Their discovery of topological effects in solid-state physics is only the most recent example. (See also an Article this week on topological quantum chemistry (page 298) and the associated News \& Views on page 287.)

Maths is often described as the language in which the laws of nature are written. Most physicists can get by in this language, but it's still a foreign tongue and important distinctions are sometimes lost in translation. Maths and theoretical physics remain distinct disciplines, with largely different methods and priorities, and - with some exceptions - pursued by separate communities.

Some of the divergence is down to history. Maths has much older roots: it existed for millennia before Isaac Newton invented infinitesimal calculus as a way to lay the foundations of physics. There are cultural differences too. Most mathematicians pursue knowledge for its own sake, and typically consider ideas to be 'deep' if they establish surprising connections between different branches of maths. Physicists tend to be interested in mathematical theories only to the extent that those theories formalize or elucidate some physical phenomenon.

And mathematicians and physicists often disagree on what questions are interesting or important. Take the quantum theory of electromagnetism, for example, the field to which Dyson made his most notable contributions. It is arguably the 'most correct' scientific theory in history, because it predicts the results of experiments with unparalleled precision. But its mathematical foundations are still somewhat less than rigorous, from a mathematician's perspective. In his 1972 remarks, Dyson identified this as a possible area where maths and physics needed to be reconciled.

Dyson traced the tension between the two disciplines to the second half of the nineteenth century, when mathematicians were slow to recognize the significance of James Clerk Maxwell's (pre-quantum) equations of electromagnetism. Others have blamed the communities' divergence on mathematicians such as Hermann Weyl, who helped to lay the foundations of quantum mechanics but then failed to communicate his ideas in terms to which the typical physicist could relate.

"Many of the major breakthroughs in topology were inspired by physics ideas."
Still, maths will usually find a way. Most big maths ideas are found reflected somewhere in the Universe and are relevant to physicists' attempts to understand it, even if it takes a while for the connection to be made. It happened to some of Srinivasa Ramanujan's obscure writings in mathematical analysis from a century ago, which have emerged to be of possible significance in the quest to understand black holes.

Physicist Eugene Wigner famously dubbed this "the unreasonable effectiveness of mathematics in the natural sciences". But a lesserknown phenomenon is what can be called the unreasonable effectiveness of physics in mathematics. In particular, the roots of the interactions between physics and topology go deeper, and many of the major breakthroughs in topology of the past few decades were inspired by physics ideas. Solving equations from quantum physics, for example, has led topologists to discover surprising and exotic phenomena in $4 \mathrm{D}$ space.

The path that mathematicians and physicists share has rarely run smooth. But at least they are both heading in the same direction. They should keep talking - every now and then, with a little more conversation, they can leave science all shook up.

\section{Internal exile}

\section{Arguments about the environmental benefits of petrol or diesel engines are outdated.}

$\mathrm{I}$ $\mathrm{n}$ Arizona, you can do it for 5 minutes, and longer when it gets warm. If it's cold, then in Connecticut you can stay at it all night. Do it in London and you will now be fined $£ 80$ (US\$104). And please do keep it away from schools.

To sit in a stationary vehicle with the engine running might seem a pointless waste of fuel, but a surprisingly high number of drivers do it for hours on end. From truck drivers who want to keep the lights and air conditioning running while they rest to commuters in Alaska who need their car to start in the morning, engine idling is a traditional and beneficial part of many road users' routines.

But now it's time to stop, say health officials in the United Kingdom. They are starting to crack down on parents who idle away in their cars at the kerbside as they wait for children to emerge from school. It's an unnecessary source of air pollution, the officials argue, and part of the reason why $59 \%$ of people in the United Kingdom live in areas where nitrogen dioxide pollution is above legal levels.

Banning idling outside schools is a sensible move. It comes as the focus on the environmental impact of the internal-combustion engine is in many cases switching away from its contribution of carbon dioxide to global warming, and instead towards exhaust pollutants that have a more immediate local impact on air quality.

The switch is most evident in the harder line that many cities are taking on diesel engines. Diesel-fuelled cars were previously encouraged with cuts in fuel duty, vehicle tax and other incentives because they produced less $\mathrm{CO}_{2}$ than petrol-fuelled vehicles, but now they are in the environmental firing line because they often yield more nitrogen oxides and particulate matter. From October, drivers of older diesel models will pay more to enter London and, under current plans, the restrictions will tighten in future to cover even the newest models. The mayors of Paris, Athens, Madrid and Mexico City have pledged an outright diesel ban by 2025. And in January this year, Oslo forced diesel drivers to stay off the roads for a day to combat a spike in air pollution.

The image of diesel as a cleaner fuel was hardly helped by the 2015 scandal in which the German car manufacturer Volkswagen was caught cheating on emission tests. The company's diesel vehicles were found to be much more polluting than Volkswagen had claimed.

So, is petrol now good and diesel bad? Not quite - at least according to an analysis of the two engine types published this week in the journal Scientific Reports (S. M. Platt et al. Sci. Rep. 7, 4926; 2017). There is no dispute on nitrogen oxides: combustion of diesel simply produces much more of them than burning petrol, and that's damaging because the gases can aggravate respiratory and cardiovascular conditions. (As well as having indirect effects such as the generation of low-level ozone.)

But the picture is less clear-cut when it comes to a different exhaust pollutant. According to the analysis, newer diesel engines actually spew out less toxic sooty waste than petrol versions. That's because most of the carbonaceous particulate matter produced when the fuel is burnt is trapped by the filters that are fitted to modern diesel vehicles. The difference is especially pronounced in cold conditions, and the scientists concluded that "diesel cars are not necessarily worse polluters than gasoline cars".

Put another way, petrol cars are not always cleaner. So why not do away with diesel and petrol engines altogether? The Swedish carmaker Volvo pledged to do just that earlier this month, saying that all new models will be battery-driven or hybrid by 2019. And France and Germany, among other countries, have made plans to drive both petrol and diesel cars from the road. It sounds good for the environment, but the issue then, of course, is how to generate the electricity needed to replace the liquid fuel. Britain's National Grid said this week that increased demand for vehicle charging could soak up the output of an entire major nuclear power station by 2030. Maybe more people could, well, walk? 